\title{
SEM Comparison of Penetration in Artificial White Spots Lesion between an Infiltrant Resin and Two Adhesive Systems
}

\author{
Ximena Zamorano', Vladimir Valenzuela1 ${ }^{1}$, Alejandro Daniels ${ }^{2}$, Agustín Iturain ${ }^{2}$ \\ ${ }^{1}$ Department of Restorative Dentistry, Dental School Universidad Mayor, Santiago, Chile \\ ${ }^{2}$ Postgraduate Program of Restorative Dentistry, Dental School, Universidad Mayor, Santiago, Chile \\ Email: vladyva58@gmail.com
}

How to cite this paper: Zamorano, $X$., Valenzuela, V., Daniels, A. and Iturain, A. (2017) SEM Comparison of Penetration in Artificial White Spots Lesion between an Infiltrant Resin and Two Adhesive Systems. Open Journal of Stomatology, 7, 147-157. https://doi.org/10.4236/ojst.2017.73010

Received: November 7, 2016

Accepted: March 10, 2017

Published: March 13, 2017

Copyright $\odot 2017$ by authors and Scientific Research Publishing Inc. This work is licensed under the Creative Commons Attribution International License (CC BY 4.0).

http://creativecommons.org/licenses/by/4.0/

\begin{abstract}
White spot infiltration emerged as an alternative of non-invasive treatment to halt progression of the lesion, through the use of low viscosity resins that would permeate the porous enamel and form a physical barrier that would prevent the acid diffusion produced by micro-organisms. Purpose: To compare penetration levels in artificial white spot lesions, of infiltrant resin $\mathrm{ICON}^{\mathrm{TM}}$ and 2 conventional adhesives systems, XP-Bond ${ }^{\mathrm{TM}}$ and Single Bond $2^{\mathrm{TM}}$. Methodology: White spot lesions (ICDAS code 2) were caused in 75 premolars or third molars were extracted in good conditions, by immersion in a $0.1 \mathrm{M}$ lactic acid solution ( $\mathrm{pH} 4.5$ ) at $37^{\circ} \mathrm{C}$ for 8 weeks. They were divided randomly into 3 groups of 25 samples and applied the following resins, Group A: ICON ${ }^{\mathrm{TM}}, \mathrm{B}: \mathrm{XP}-$ Bond $^{\mathrm{TM}}$ and C: Single Bond $2^{\mathrm{TM}}$. Subsequently, the enamel was removed with hydrochloric acid to expose resin saturated area and the samples were metalized with $\mathrm{Au}-\mathrm{Pd}$ for SEM observation. The resin tags lengths were measured on microphotographs through software, and the values were analyzed with the statistics ANOVA and Scheffé post-test. Results: There were significant differences $(\mathrm{p}<0.05)$ in penetration of $\operatorname{ICON}^{\mathrm{TM}}(82.7$ $\mu \mathrm{m} \pm 26.8 \mu \mathrm{m})$ compared to adhesive systems XP-Bond ${ }^{\mathrm{TM}}(58.5 \mu \mathrm{m} \pm 29.3$ $\mu \mathrm{m})$ and Single Bond $2^{\mathrm{TM}}(44.8 \mu \mathrm{m} \pm 32.5 \mu \mathrm{m})$. We found no significant differences between the two adhesive systems $(p>0.05)$. Conclusion: Under the conditions tested, the penetration of infiltrant ICON was significantly higher than the adhesive systems; however, it removes the surface layer of the enamel.
\end{abstract}

\section{Keywords}

Artificial White Spot Lesions, Resins Penetration, Etch and Rinse Adhesives, SEM 


\section{Introduction}

The dental paradigm about the emergence of white spot lesions has progressed towards a higher preservation of healthy dental tissues, which is now known as minimally invasive dentistry [1] [2] [3]. Re-mineralization process obtained with fluoride treatment is not fast, moreover is not always achieved, part of the reason that resin infiltration procedure arose 40 years ago as an alternative treatment for white spot lesions, stopping the advance of the lesion by infiltrating low viscosity resins, capable of spreading through the porous enamel structure [4] [5] [6]. These monomers once polymerized form a physical barrier against acid diffusion produced by microorganisms, as well as they prevented the release of calcium and phosphate ions from enamel, despite the acid medium [7] [8].

This therapeutic option is physically sustained because the mineral loss occurs predominantly in the sub-surface of enamel, which allows an increment in porosity at this level, while the surface is less demineralized, giving it a healthy appearance [9] [10]. For this reason, the infiltrant resins, which have physical characteristics such as low viscosity, low contact angle with enamel and low surface tension, should be able to reach this level [11] [12].

In 2007, Paris et al. developed a research line using conventional adhesives by modifying its composition (primarily Bis-GMA, TEGDMA, HEMA and ethanol), with the aim of improving penetration capacity of material [5]. The result of their investigations was the creation of an infiltrant resin marketed ICON ${ }^{\mathrm{TM}}$ (DMG, Hamburg, Germany), designed specifically for treatment of white spot lesions [13] [14]. Even though its clinical use is actually increasing nowadays, there is not enough independent scientific evidence to promote its application, since most studies were carried out by the same group of researchers that created this resin [15] [16] [17] [18].

The purpose of this work is to determine through the SEM observation the penetration depth in artificial white spot lesions (ICDAS code 2) of infiltrant re$\sin \mathrm{ICON}^{\mathrm{TM}}$ and compare it with two conventional adhesive systems of low viscosity and broad clinical use, XP-Bond ${ }^{\mathrm{TM}}$ (Dentsply Caulk, Milford, DE, USA) and Single Bond $2^{\mathrm{TM}}$ (3M-ESPE, St Paul, MN, USA).

\section{Materials and Methods}

Prior informed consent of patients, 75 healthy teeth were collected (40 premolars and 35 third molars with extractive indication, without cavities, white spots lesion or restorations), were cleaned by using a brush and prophylactic paste and then stored in deionized water at $37^{\circ} \mathrm{C}$ until use (Dry Oven ${ }^{\mathrm{TM}}$, WTC, Binder, Germany). These teeth roots were sectioned, leaving the crown, and the pulp chamber was sealed with glass ionomer cement (Vitremer ${ }^{\mathrm{TM}}$, 3M-ESPE, St Paul, MN, USA). Each crown was covered with nail varnish, leaving a $6 \times 6 \mathrm{~mm}$ window on the free sides. Subsequently, they were submerged in a Lactic Acid solution ( $\alpha$-hidroxy-propanoic acid $0.1 \mathrm{M}, \mathrm{pH} 4.5$ stabilized with $\mathrm{NaOH}$ ), and kept in dry oven for 8 weeks at $37^{\circ} \mathrm{C}$. This solution was renewed twice per week, until white spot lesions were obtained, under the criteria that they were visible with its 
wet surface (ICDAS code 2).

Then, the samples were divided randomly in 3 groups of 25 each; Group A: $\mathrm{ICON}^{\mathrm{TM}}$, Group B: XP-Bond ${ }^{\mathrm{TM}}$ and Group C: Single Bond $2^{\mathrm{TM}}$ and the resins were applied according to the following protocol:

Group A (ICON Resin Infiltrant):

- Surface pre-treatment with $15 \%$ hydrochloric acid gel $\left(\mathrm{ICON}-\mathrm{Etch}^{\mathrm{TM}}\right)$ for 2 minutes

- Water rinsing for 30 seconds

- Ethanol 99\% application for 30 seconds (ICON-Dry ${ }^{\mathrm{TM}}$ )

- Air drying for 3 seconds

- Infiltrant resin application (ICON-Infiltrant ${ }^{\mathrm{TM}}$ ) during 3 minutes

- Light curing for 40 seconds

- Second application of Infiltrant resin (ICON-Infiltrant $\left.{ }^{\mathrm{TM}}\right)$ for 1 minute

- Light curing for 40 seconds (QHL 75 ${ }^{\mathrm{TM}}$, Dentsply Corporate, USA) Group B (XP-Bond) and Group C (Single Bond 2):

- Surface pre-treatment with ortho-phosphoric acid 37\% (Eco-Etch ${ }^{\mathrm{TM}}$, Ivoclar Vivadent, Liechtenstein) for 30 seconds

- Adhesive system application with microbrush (Multi Brush ${ }^{\mathrm{TM}}$, Denbur Inc, IL, USA) during 1 minute

- Air drying for 3 seconds

- Second application of adhesive system with microbrush for 1 minute

- Air drying for 3 seconds

- Light curing for 40 seconds (QHL 75 ${ }^{\mathrm{TM}}$, Dentsply Corporate, USA)

Once infiltrated each one of the white spot lesions with its respective resin, these surfaces were covered with a layer of composite in order to protect and sustain the infiltrated zone, (Filtex Supreme ${ }^{\mathrm{TM}}$, 3M-ESPE, St Paul, MN, USA) light cured during $40 \mathrm{sec}$. with the same lamp. Later, the crowns were divided in two halves by a fracture perpendicular to the surface across the infiltrated lesions, to obtain a surface which consisted of healthy enamel-resin infiltrated enamel-composite (Figure 1).

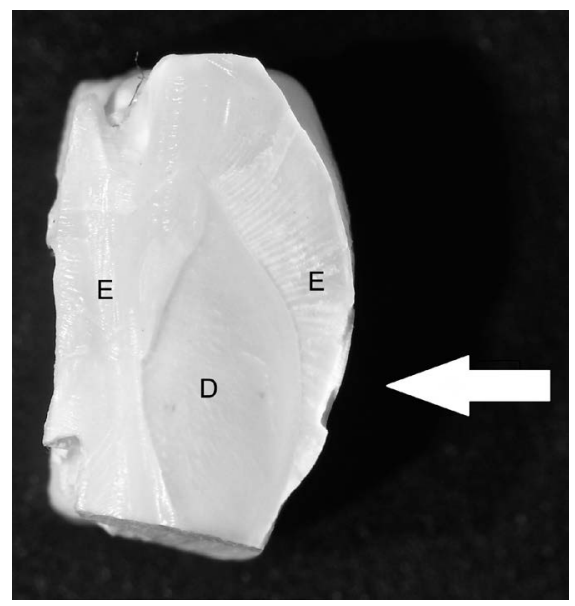

Figure 1. Longitudinal crown fracture with artificial white spot lesion on vestibular surface, infiltrated by resin (arrow). $\mathrm{E}=$ enamel, $\mathrm{D}=$ dentine. 
Then, part of the enamel was dissolved and eliminated with hydrochloric acid application for 15 minutes on the infiltrated zone, eliminating the enamel surrounding the resin tags in order to expose them.

Once prepared these samples were metalized with $\mathrm{Au}-\mathrm{Pd}$ and were observed at Scanning Electron Microscope (TM-3000 ${ }^{\mathrm{TM}}$, Hitachi High Technologies Corporation, Tokyo, Japan) to $500 \times$ and $1000 \times$. They were analyzed by a software Image-Pro Premiere ${ }^{\mathrm{TM}}$ v.9.1 (Media Cybernetics) and the depth of penetration of the resins was quantified.

We obtained 75 microphotographs to $1000 \times, 4$ of them were eliminated because the structures formed by the resin infiltration were not easily visible and measurable. In each microphotograph the most complete and easily recognizable resin tags to be measured were selected from its base at the surface to the terminal zone located in greater depth. Each tag on the microphotographs was measured and then averaged to obtain a value per image.

After that, data were tabulated and analyzed statistically with ANOVA and post-test Scheffé.

The $\mathrm{p}$ values less than 0.05 were considered significant.

\section{Results}

Microphotographs at $500 \times$ were used to have a general view of the samples, and the 1000x images were analyzed with Image-Pro Premiere software. The most intact and easily identifiable resin tags were measured in each microphotograph, and obtained mean values among them. The most representative images of results are shown below [Figure 2(a), Figure 2(b), Figure 3(a) and Figure 3(b)].

The values obtained by measuring the tags corresponding to different resins were tabulated and sorted out in the following Table 1 and Graphic 1.

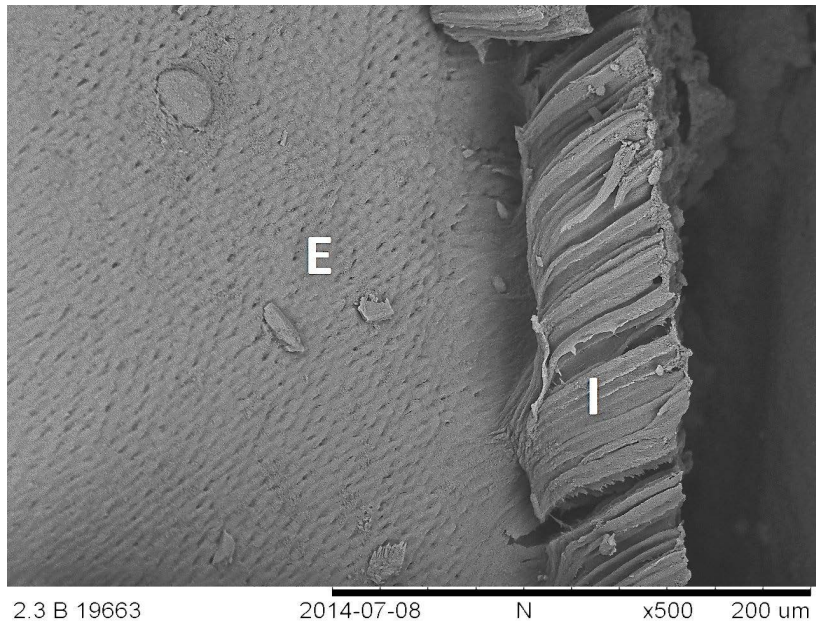

(a)

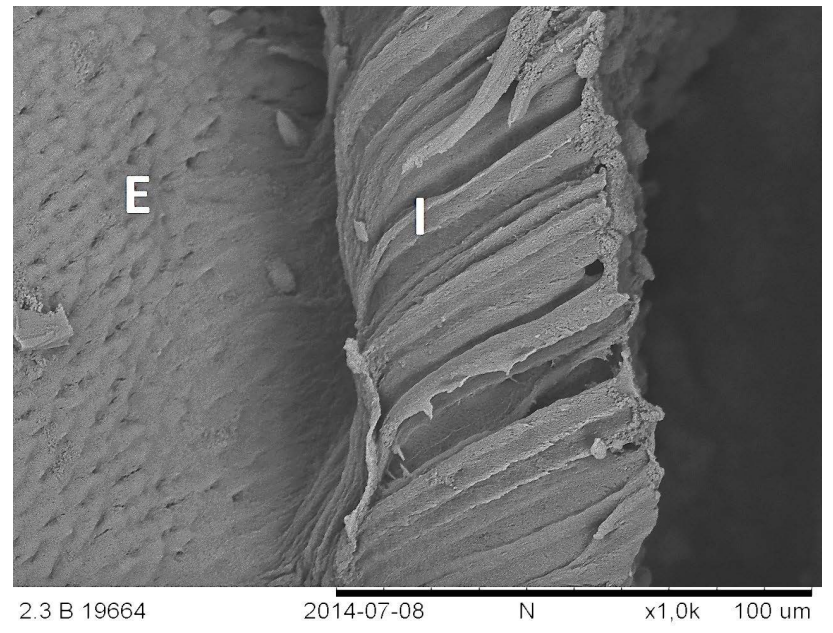

(b)

Figure 2. Enamel artificial white spot lesion infiltrated with $\mathrm{ICON}^{\mathrm{TM}}$ : (a) $500 \times$ on the left shows etched enamel and on the right, a band of uniform thickness composed by multiple resin tags; (b) In the same area at $1000 \times$, it's confirmed that the presence of a large number of these structures, whose length was measured, getting a mean of $(71.7 \pm 4.4) \mu \mathrm{m}$, and its thickness varied between $4 \mu \mathrm{m}$ and $8 \mu \mathrm{m}$. Morphologically, the tags show an irregular surface, and cylindrical or tapered shape. E = Etched enamel; $\mathrm{I}=$ ICON. 


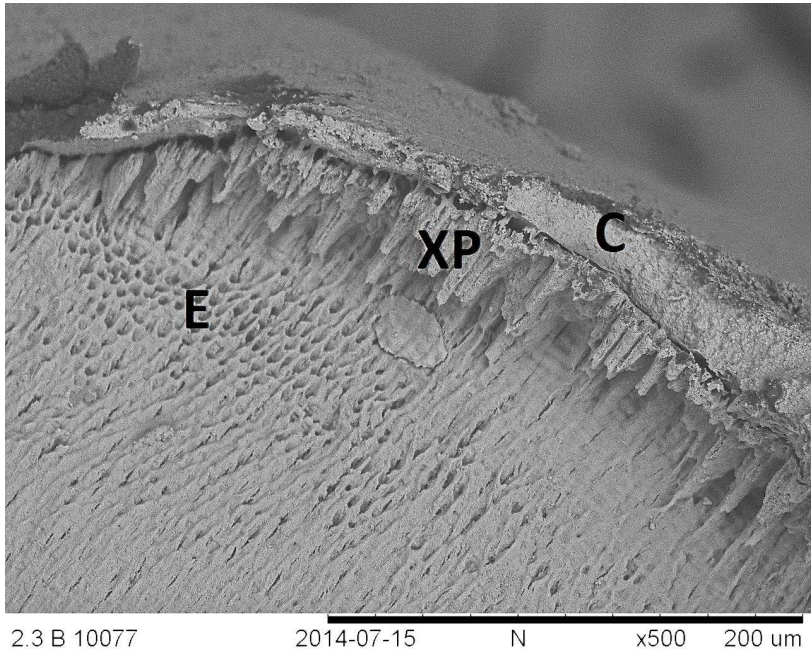

(a)

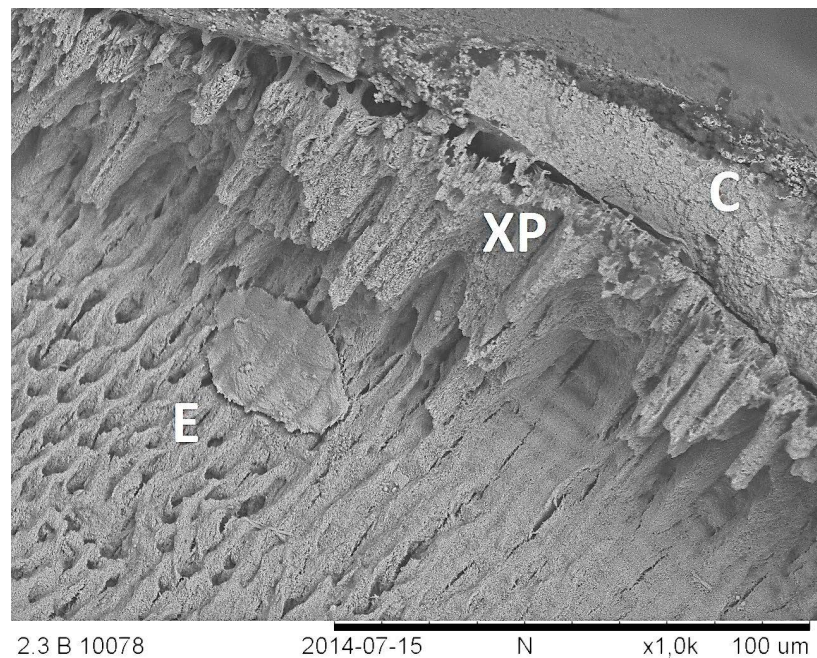

(b)

Figure 3. Enamel artificial white spot lesion infiltrated with XP-Bond ${ }^{\mathrm{TM}}$ : (a) The left image at $500 \times$ shows resin tags of various lengths, etched enamel and on top of that, the composite; (b) The 1000× image shows that the resin tag length has a mean of $(35.09 \pm 12) \mu \mathrm{m}$, its thickness is homogeneous and apparently hollow. Fewer tags are shown on Figure 3 in comparison to Figure 2. $\mathrm{C}=$ Composite; $\mathrm{XP}=\mathrm{XP}-$ Bond; $\mathrm{E}=$ Etched enamel.

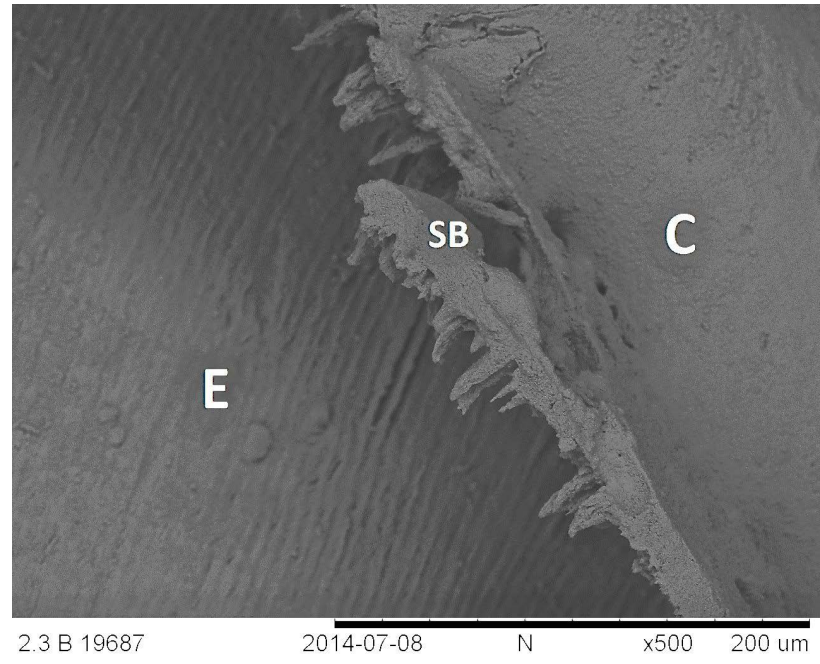

(a)

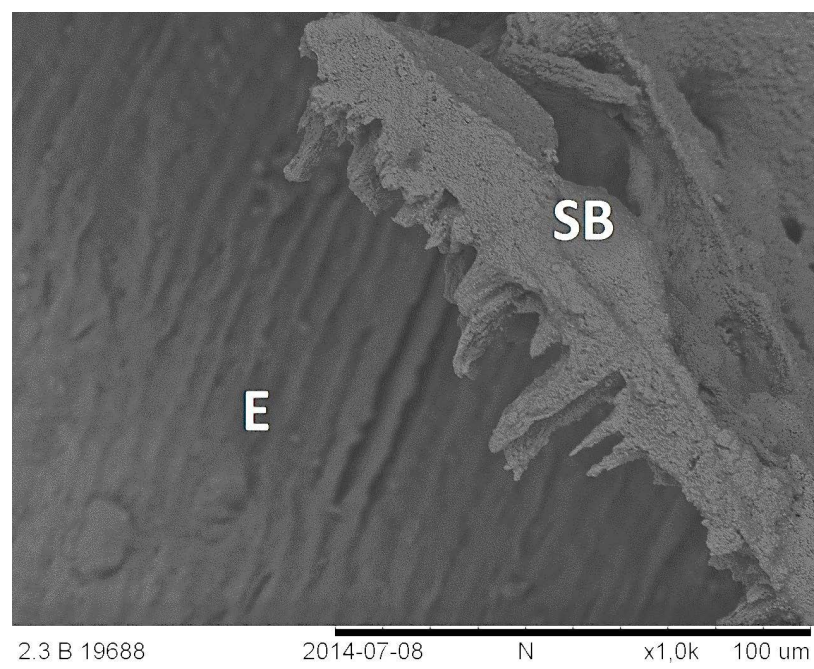

(b)

Figure 4. Enamel artificial white spot lesion infiltrated with Single Bond $2^{\mathrm{TM}}$ : (a) At $500 \times$ can be observed the composite on the right, etched enamel on the left and an adhesive layer in the center; (b) 1000× image shows even fewer and shorter tags, with irregular surface, and a mean length of $17.80 \mu \mathrm{m} \pm 9.51 \mu \mathrm{m}$. Fewer and shorter tags are shown on Figure 4 in comparison to Figure 2 . $\mathrm{C}=$ Composite; $\mathrm{E}=$ Enamel; $\mathrm{SB}=$ Single Bond 2 .

Table 1. Mean values of depth penetration of different resins used for artificial white spot lesion infiltration.

\begin{tabular}{ccccc}
\hline RESIN & N & MEAN & SD & 26.83 \\
\hline ICON & 24 & 82.67 & \pm & 29.34 \\
XP-BOND & 25 & 58.53 & \pm & 32.45 \\
SINGLE BOND & 22 & 44.83 & \pm \\
\hline
\end{tabular}

ANOVA F: $9.78 ; \mathrm{p}<0.005$. 


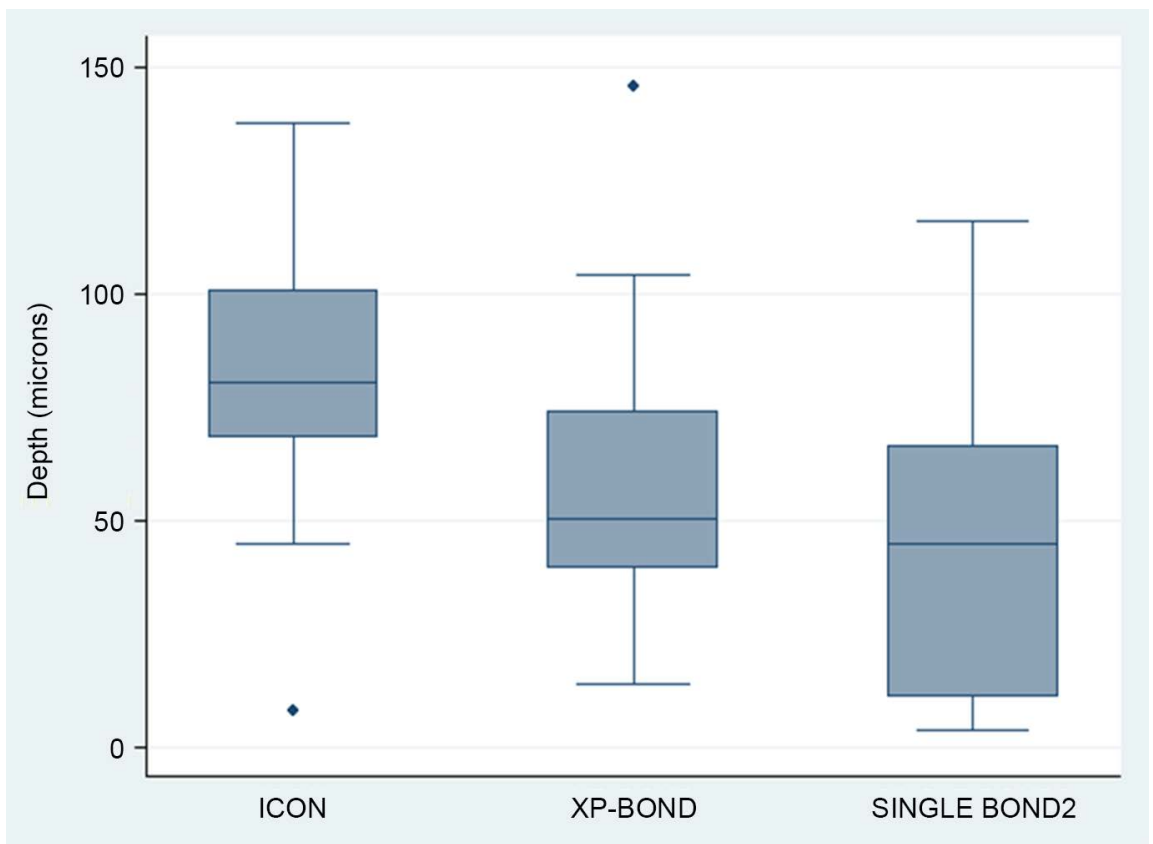

Graphic 1. Box plot that represents depth penetration of the resins used for artificial white spot infiltration.

\section{Statistical Analysis}

The ANOVA test found statistically significant differences among the groups A, $B$ and $C(p<0.05)$. Scheffé post-test proved significant differences between groups $A$ and $B(p<0.05)$ and between groups $A$ and $C(p<0.05)$. No significant differences were found between groups $B$ and $C(p>0.05)$.

\section{Discussion}

White spot infiltration process, according to Dávila et al., refers to certain low-molecular weight monomers which have the capacity of flowing and filling the micropores present in white spot lesions [6]. In our study we observed that the infiltrant resin certainly has the ability to penetrate enamel affected by artificial white spot lesion. While infiltrant ICON ${ }^{\mathrm{TM}}$ performed better than adhesives systems, some studies have reported that in order to stop the progression of white spot lesion, penetration depth of $60 \mu \mathrm{m}$ is necessary, and this is achieved with Icon infiltrant. However conventional adhesives systems under the tested conditions are not far from this value either [19].

Reviewing works that quantify the penetration depth, we found a wide range of results that may differ or were similar to ours. This could be explained by the use of different microscopic observation techniques, which involve the use of stains incorporated into low viscosity resins, however, it has not been determined if their physical behavior was affected. Scanning Electron Microscopy allows a more objective observation of resin tags, without using chemical agents that might influence the ability of the infiltrant agents [20].

With the used experimental conditions, the penetration values obtained were lower than those reported by Meyer-Lueckel et al. (2011), where using natural 
white spot treated with infiltrant resin and observing them with confocal microscopy, their penetration depth value was $414 \mu \mathrm{m}$ [21]. Another study, by Paris et al. (2012) also achieved higher results than ours, in which infiltrated natural white spots in primary teeth with ICON at different application times, obtaining penetration values of $286 \mu \mathrm{m}(\mathrm{SD}=212.38 \mu \mathrm{m})$ [14].

Our results were similar to those reported by Dávila et al. (1975), who analyzed through Optical Microscopy the penetration of a resin based on Resorcinol-formaldehyde. The depth obtained was in the order of $40-60 \mu \mathrm{m}$, but it is important to consider that they experimented with artificial white spots lesions in monkey's teeth [6].

Another study with similar results was Paris et al. (2007), who observed resin infiltrant penetration in incipient natural white spot lesions using confocal microscopy. This work compared pre-treatment of enamel with a $15 \% \mathrm{HCl}$ gel versus a $37 \%$ orthophosphoric acid gel, and found penetration differences of 58 $\mu \mathrm{m}(\mathrm{SD}=37 \mu \mathrm{m}) \mathrm{v} / \mathrm{s} 18 \mu \mathrm{m}(\mathrm{SD}=11 \mu \mathrm{m})$ respectively [22]

The values obtained in our study were higher than those reported by Subramaniam et al. (2014), who also artificially induced white spot lesions and measured the penetration depth with ICON infiltrant ${ }^{\mathrm{TM}}$ with stereomicroscopy, finding values in the order of $6.06 \mu \mathrm{m}$. $(\mathrm{SD}=3.31 \mu \mathrm{m})$ [23]. Thereby, we believe that our experimental model could have more accuracy in measuring the length of tags formed through infiltration with different resins.

These differences in penetration depth could depend on different factors, including:

1) White spot lesion origin: natural or induced artificially.

2) Surface pre-treatment.

3) Chemical composition and infiltrant characteristics.

4) Application time of Infiltrant.

Regarding to the origin of white spot lesion, there are differences on the Infiltration process. In natural white spot lesion the enamel is in a dynamic process of re-mineralization and demineralization, increasing resistance to acid attack and also incorporating organic molecules [4] [5]. These intraoral conditions reduces the micropores size produced in white spot lesion, explaining the greater resin penetration in artificially induced caries, in absence of those conditions [5] [19].

To enable the low viscosity resin infiltration is mandatory to perform an enamel surface pre-treatment, in order to eliminate or perforate the white spot surface area, whose thickness is from 20 to $50 \mu \mathrm{m}$. This has been considered by some authors as an obstacle to reach an effective monomers penetration to the lesion body [16] [24] [25]. According to Hyun-Kyung et al. (2014), who compared the use of $15 \% \mathrm{HCl} \mathrm{v/s} \mathrm{37 \%} \mathrm{orthophosphoric} \mathrm{acid} \mathrm{application,} \mathrm{removal} \mathrm{of}$ surface enamel values were greater for $\mathrm{HCl}(36 \mu \mathrm{m} \pm 7.6 \mu \mathrm{m})$ than orthophosphoric acid $(13 \mu \mathrm{m} \pm 2.7 \mu \mathrm{m})$ [25]. Even though they demonstrated that infiltrant penetration increases with pre-treatment with Hydrochloric acid, we believe that the surface layer preservation is important for the treatment results 
predictability. The 15\% hydrochloric acid application for 2 min could remove more hydroxyapatite crystals than necessary or even eliminate completely the enamel surface, for this reason we should opt for a less aggressive pre-treatment that improves the permeability, avoiding the complete removal of enamel surface layer.

Resin composition is an important issue, since it is related with its penetration ability. Regarding proportion and monomers types, ICON infiltrated ${ }^{\mathrm{TM}}$ has a high content of TEGDMA, a low viscosity monomer and low molecular weight, with high conversion degree [12] [26]. These properties confer a great potential for penetration, however although it is hydrophobic, its water sorption capacity make it more susceptible to be hydrolyzed within on oral environment [27].

XP-Bond ${ }^{\mathrm{TM}}$ Adhesive System has a high fluidity, despite its content of UDMA and TEGDMA, both with high molecular weight and hydrophobic, with limited water solubility. It contains HEMA, a low molecular weight and hydrophilic monomer, with low viscosity and high water sorption ability therefore more vulnerable to hydrolysis [28].

Single Bond $2^{\mathrm{TM}}$ adhesive is composed principally of Bis-GMA, a high molecular weight and highly viscous monomer, and also HEMA, that improves its fluidity [12] [28]. With the purpose of improving the mechanical properties and reducing polymerization shrinkage, Single Bond $2^{\mathrm{TM}}$ has in its composition colloidal silica as a filler, which could modify resin viscosity, in detriment to the infiltration process, this could explain the lower values reached for resin tag length [12].

In order to get adhesion on moisture conditions and increase fluidity, adhesive systems have solvents in their composition but these could affect their polymerization degree and their mechanical properties. The kind of solvent in tested adhesives systems could also influence on depth penetration [12] [29].

As well as the penetration capability of an infiltrant is an important issue to achieve positive results in stopping the progression of incipient lesions, there are other factors that also affect the efficacy of these materials and should be analyzed, such as resin tags density, sealing quality, resistance to acid attack, surface micro-hardness, the effectiveness and stability over the long term.

\section{Conclusions}

Under the tested experimental conditions, ICON resin infiltrant obtained the deepest penetration of artificial caries with a mean value of $82.66 \mu \mathrm{m}$ ( $\mathrm{SD}=$ $26.82 \mu \mathrm{m})$. There were significant differences among ICON and conventional adhesive systems $(\mathrm{p}<0.05)$.

The XP-Bond ${ }^{\mathrm{TM}}$ and Single Bond $2^{\mathrm{TM}}$ adhesive systems reached a penetration mean value of $58.53 \mu \mathrm{m}(\mathrm{SD}=29.33 \mu \mathrm{m})$ and $44.83 \mu \mathrm{m},(\mathrm{SD}=32.45 \mu \mathrm{m})$ respectively, without a significant difference between them. Despite ICON efficacy in penetration, pre-treatment with hydrochloric acid for 2 minutes, removes the enamel surface layer.

Clinical Relevance: Micro-invasive therapies are relevant in order to avoid 
healthy dental tissue destruction. The knowledge and understanding of physical and biological behavior of these materials is priority for an advanced dental practice.

\section{Funding}

This work was partially financed by Colgate-Palmolive Grant.

\section{References}

[1] Featherstone, J.D. and Doméjean, S. (2012) Minimal Intervention Dentistry: Part 1. From 'Compulsive' Restorative Dentistry to Rational Therapeutic Strategies. British Dental Journal, 213, 441-445. https://doi.org/10.1038/sj.bdj.2012.1007

[2] Fejerskov, O., Kidd, E., Nyvad, B. and Baelum, V. (2008) Dental Caries: The Disease and Its Clinical Management. 2nd Edition, Blackwell Munksgaard Ltd, Oxford, $19-48$.

[3] Meyer-Lueckel, H., Paris, S. and Ekstrand, K. (2013) Caries Management-Science and Clinical Practice. Thieme Publishing Group, Stuttgart, 40-68. https://doi.org/10.1055/b-002-85484

[4] Jefferies, S.R. (2014) Advances in Remineralization for Early Carious Lesions: A Comprehensive Review. Compendium of Continuing Education in Dentistry, 35, 237-243.

[5] Li, X., Wang, J., Joiner, A. and Chang, J. (2014) The Remineralisation of Enamel: A Review of the Literature. Journal of Dentistry, 42, s12-s20.

https://doi.org/10.1016/s0300-5712(14)50003-6

[6] Dávila, J.M., Buonocuore, M.G., Greeley, C.B. and Provenza, D.V. (1975) Adhesive Penetration in Human Artificial and Natural White Spots. Journal of Dental Research, 54, 998-1008.

[7] Albamonte, G.S., Sfalcin, R.A., Freire, T.G., Bruschi, R.C. and Puppin, R.M. (2013) Evaluation of Polymerization Characteristics and Penetration into Enamel Caries Lesions of Experimental Infiltrants. Journal of Dentistry, 41, 1014-1019. https://doi.org/10.1016/j.jdent.2013.08.019

[8] Chen, H., Liu, X., Dai, J., Jiang, Z., Guo, T. and Ding, Y. (2013) Effect of Remineralizing Agents on White Spot Lesions after Orthodontic Treatment: A systematic Review. American Journal of Orthodontics and Dentofacial Orthopedics, 143, 376382. https://doi.org/10.1016/j.ajodo.2012.10.013

[9] Kidd, E.A. and Fejerskov, O. (2004) What Constitutes Dental Caries? Histopathology of Carious Enamel and Dentin Related to the Action of Cariogenic Biofilms. Journal of Dental Research, 83, c35-c38. https://doi.org/10.1177/154405910408301s07

[10] Nicola, X., West, N.X. and Joiner, A. (2014) Enamel Mineral Loss. Journal of Dentistry, 42, s2-s11. https://doi.org/10.1016/S0300-5712(14)50002-4

[11] Phark, J.H., Duarte Jr, S., Meyer-Lueckel, H. and Paris, S. (2009) Caries Infiltration with Resins: A Novel Treatment Option for Interproximal Caries. Compendium of Continuing Education in Dentistry, 30, 13-17.

[12] Van Landuyt, K.L., Snauwaert, J., De Munck, J., Peumans, M., Yoshida, Y., Poitevin, A., Coutinho, E., Suzuki, K., Lambrechts, P. and Van Meerbeek, B. (2007) Systematic Review of the Chemical Composition of Contemporary Dental Adhesives. Biomaterials, 28, 3757-3785. https://doi.org/10.1016/j.biomaterials.2007.04.044

[13] Paris, S. and Meyer-Lueckel, H. (2010) Infiltrants Inhibit Progression of Natural 
Caries Lesions In Vitro. Journal of Dental Research, 89, 1276-1280. https://doi.org/10.1177/0022034510376040

[14] Paris, S., Soviero, V.M., Seddig, S. and Meyer-Lueckel, H. (2012) Penetration Depths of an Infiltrant into Proximal Caries Lesions in Primary Molars after Different Application Times In Vitro. International Journal of Paediatric Dentistry, 22, 349-355. https://doi.org/10.1111/j.1365-263X.2011.01204.X

[15] Attal, J.P., Atlan, A., Denis, M., Vennat, E. and Tirlet, G. (2014) White Spots on Enamel: Treatment Protocol by Superficial or Deep Infiltration (Part 2). International Orthodontics, 12, 1-31.

[16] Jia, L., Stawarczyk, B., Schmidlin, P.R., Attin, T. and Wiegand, A. (2012) Effect of Caries Infiltrant Application on Shear Bond Strength of Different Adhesive Systems to Sound and Demineralized Enamel. The Journal of Adhesive Dentistry, 14, 569574.

[17] Kielbassa, A.M., Müller, J. and Gernhardt, C.R. (2009) Closing the Gap between Oral Hygiene and Minimally Invasive Dentistry: A Review on the Resin Infiltration Technique of Incipient (Proximal) Enamel Lesions. Quintessence International, 40, 663-681.

[18] Mikhael, M., Mendes, V., da Silva, T., Lenzi, M., Masterson, D., Trindade, C., Ribeiro, I.P. and Cople, L. (2014) Is Non-Cavitated Proximal Lesion Sealing an Effective Method for Caries Control in Primary and Permanent Teeth? A Systematic Review and Meta-Analysis. Journal of Dentistry, 42, 1217-1227. https://doi.org/10.1016/j.jdent.2014.07.015

[19] Schmidlin, P.R., Sener, B., Attin, T. and Wiegand, A. (2012) Protection of Sound Enamel and Artificial Enamel Lesions against Demineralisation: Caries Infiltrant versus Adhesive. Journal of Dentistry, 40, 851-856. https://doi.org/10.1016/j.jdent.2012.07.003

[20] Van Meerbeek, B., Vargas, M., Inoue, S., Yoshida, Y., Perdigão, J., Lambrechts, P., et al. (2000) Microscopy Investigations. Techniques, Results, Limitations. American Journal of Dentistry, 13, 3D-18D.

[21] Meyer-Lueckel, H., Chatzidakis, A., Naumann, M., Dörfer, C.E. and Paris, S. (2011) Influence of Application Time on Infiltrant Penetration into Natural Enamel Caries. Journal of Dentistry, 39, 465-469. https://doi.org/10.1016/j.jdent.2011.04.003

[22] Paris, S., Meyer-Lueckel, H. and Kielbassa, A.M. (2007) Resin Infiltration of Natural Caries Lesions. Journal of Dental Research, 86, 662-666. https://doi.org/10.1177/154405910708600715

[23] Subramaniam, P., Girish Babu, K.L. and Lakhotia, D. (2014) Evaluation of Penetration Depth of a Commercially Available Resin Infiltrate into Artificially Created Enamel Lesions: An In Vitro Study. Journal of Conservative Dentistry, 17, 146-149. https://doi.org/10.4103/0972-0707.128054

[24] Yim, H.-K., Kwon, H.-K., and Kim, B.-I. (2014) Modification of Surface Pre treatment for Resin Infiltration to Mask Natural White Spot Lesions. Journal of Dentistry, 42, 588-589. https://doi.org/10.1016/j.jdent.2014.01.015

[25] Yim, H.-K., Min, J.-H., Kwon, H.-K. and Kim, B.-I. (2014) Modification of Surface Pretreatment of White Spot Lesions to Improve the Safety and Efficacy of Resin Infiltration. Korean Journal of Orthodontics, 44,195-202. https://doi.org/10.4041/kjod.2014.44.4.195

[26] Peutzfeldt, A. (1997) Resin Composites in Dentistry: The Monomer Systems. European Journal of Oral Sciences, 105, 97-116. https://doi.org/10.1111/j.1600-0722.1997.tb00188.x 
[27] Malacarne, J., Carvalho, R.M., de Goes, M.F., Svizero, N., Pashley, D.H., Tay, F.R., Yiu, C.K. and Carrilho, M.R. (2006) Water Sorption/Solubility of Dental Adhesive Resins. Dental Materials, 22, 973-980. https://doi.org/10.1016/j.dental.2005.11.020

[28] Gonçalves, F., Kawano, Y., Pfeifer, C., Stansbury, J.W. and Braga, R.R. (2009) Influence of BisGMA, TEGDMA and BisEMA Contents on Viscosity, Conversion and Flexural Strength of Experimental Resins and Composites. European Journal of Oral Sciences, 117, 442-446. https://doi.org/10.1111/j.1600-0722.2009.00636.x

[29] Nakaoki, Y., Nikaido, T., Burrow, M.F. and Tagami, J. (2002) Effect of Residual Water on Dentin Bond Strength and Hybridization of a One Bottle Adhesive System. Operative Dentistry, 27, 563-568.

\section{Submit or recommend next manuscript to SCIRP and we will provide best} service for you:

Accepting pre-submission inquiries through Email, Facebook, LinkedIn, Twitter, etc. A wide selection of journals (inclusive of 9 subjects, more than 200 journals)

Providing 24-hour high-quality service

User-friendly online submission system

Fair and swift peer-review system

Efficient typesetting and proofreading procedure

Display of the result of downloads and visits, as well as the number of cited articles

Maximum dissemination of your research work

Submit your manuscript at: http://papersubmission.scirp.org/

Or contact ojst@scirp.org 